\title{
In health care, geography is destiny
}

\author{
William C. Nugent, MD
}

From the Department of Cardiothoracic Surgery, Dartmouth-Hitchcock Medical Center, Lebanon, $\mathrm{NH}$.

Received for publication Aug 18, 2000; accepted for publication Aug 23, 2000.

Address for reprints: William C. Nugent, MD, Department of Cardiothoracic Surgery, Dartmouth-Hitchcock Medical Center, One Medical Center Dr, Lebanon, NH 03756.

J Thorac Cardiovasc Surg 2003;125:S2-3

Originally published in J Thorac Cardiovasc Surg 2000;120:976-7.

Copyright $\odot 2003$ by The American Association for Thoracic Surgery

$0022-5223 / 2003 \$ 30.00+0$

doi:10.1067/mtc.2003.206

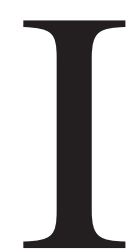

n this issue of the Journal [J Thorac Cardiovasc Surg 2000;120:978-89], Shahian and colleagues conclude that proximity to home and historical referral patterns are the two most important variables influencing where patients have heart surgery. Location and habit appear to determine where most patients seek care.

These conclusions seem surprising in this modern era of consumer empowerment-more so, given that the eight competing programs in the study lie within 15 miles of one another and in a "mature" marketplace characterized by high penetration of managed care.

However, these findings should not surprise us. A person who is experiencing illness needs help from family and friends. Getting and giving this kind of help is easier when the physical location of care is nearby and when the network of relationships among providers is familiar. Despite this, federal and private medical insurers and some health care administrators are attempting to change or control referral patterns. Typical strategies are to buy primary care practices, publish information about hospitals' and surgeons' outcomes, provide direct economic incentives to physicians and patients, and popularize "centers of excellence" to control costs, improve quality, and protect or increase clinical volume. These efforts have helped fuel public outcry against managed care that has carried the debate over a national Patients' Bill of Rights to the top of our legislators' health care agenda.

Published data suggest that patients are better informed about medical issues and they increasingly use that information to involve themselves in heath care decisions. ${ }^{1-3}$ Perhaps it is not ignorance or a lack of incentives that causes patients to resist changing where they receive care. There may be other forces at work. Finlayson and associates ${ }^{4}$ report that patients anticipating high-risk surgical procedures would accept a 2-fold to 6-fold increased risk of mortality to receive their care close to home. The present study provides empiric evidence that staying close to home and staying within a familiar referral network are high priorities for our patients.

How should we, as clinicians, respond to this study? One approach, and I believe the wrong approach, would be to assume that our patients simply do not get it yet. We could offer more incentives, publicize the "important" outcomes more aggressively, and centralize care more effectively. Pushed harder, patients would eventually see the error of their ways and would "go where they are told." This approach would intensify clinical profiling efforts, limit patient choice, and continue to pit clinician against clinician in the struggle for individual or institutional market share.

There is another alternative: we could embrace the findings described in the report by Shahian and associates. If patients generally prefer to receive care according to location and habit, then clinicians, insurers, policymakers, and institutions should accept this reality. Instead of persuading, contracting, and regulating to change the location of care, we should strive to ensure that care is of uniformly high quality regardless of where one chooses to go.

This can be achieved. A voluntary multidisciplinary collaborative of health care professionals, the Northern New England Cardiovascular Disease Study Group, has demonstrated that mortality rates for coronary revascularization across an entire geographic region can be reduced, and statistically significant institutional differences obliterated, by working together to understand and eliminate causes of adverse outcomes. ${ }^{5}$ This model draws from the collective wisdom of a regionally aligned clinical workforce determined to improve care. Pooling information from the whole 
region allows application of population-based analytic techniques that, in other settings, have been used to threaten and divide physicians and hospitals.

Boston politician Tip O'Neil was successful because he recognized that "All politics is local." Now, Dr Shahian's group reminds us that "All health care is local." If patients are to get great care wherever they choose to go, their physicians must work together to help make it happen. Regional clinical collaborative groups focused on the traditional patient-centered values of our profession can help us attain that goal.

\section{References}

1. Charles C, DeMaio S. Lay participation in health care decisionmaking. J Health Polit Policy Law. 1993;18:881-904.

2. Karlawish J. Shared decision making in critical care. Am J Crit Care. 1996;5:391-6.

3. Guadagnoli E, Ward P. Patient participation in decision making. Soc Sci Med. 1998;41:329-39.

4. Finlayson SRG, Birkmeyer JD, Tosteson ANA, Nease RF. Patient preferences for local care: implications for regionalization. Med Care. 1999;37:204-9.

5. O'Connor GT, Plume SK, Olmstead EM, et al. A regional intervention to improve the hospital mortality associated with coronary artery bypass graft surgery. JAMA. 1996;275:841-6. 